\title{
Globalization: Alternative Pricing in a Peak-Load Pricing Model
}

\section{Gerald Aranoff}

Ariel University Center of Samaria, Ariel, Israel

Email: garanoff@netvision.net.il

How to cite this paper: Aranoff, G. (2017) Globalization: Alternative Pricing in a Peak-Load Pricing Model. Modern Economy, 8, 888-896. https://doi.org/10.4236/me.2017.87062

Received: May 29, 2017

Accepted: July 15, 2017

Published: July 19, 2017

Copyright (C) 2017 by author and Scientific Research Publishing Inc. This work is licensed under the Creative Commons Attribution International License (CC BY 4.0).

http://creativecommons.org/licenses/by/4.0/ (c) (i) Open Access

\begin{abstract}
We discuss globalization and the current recession in manufacturing and construction. We present a theoretical model of globalization, of two countries, $\mathrm{X}$ and $\mathrm{Y}$, each with open-market systems domestically and internationally. We compare two pricing policies in each country: short-run marginal cost, SRMC, versus prices fixed, $\bar{P}$, over the business cycle. We present a proposition and proof. We give a detailed numerical example with graphs for each country. The main result is that $\bar{P}$ over the business cycle increases the volatility of $\mathrm{Q}$ demand over the cycle and increases consumer surplus in both countries under certain conditions. The numerical example shows a drawback of SRMC pricing under demand fluctuations-that the required price in high-demand times to balance accounts becomes extremely high. Consumers are better off with $\bar{P}$, paying a small increase over SRMC in the off-peak, $6 / 7^{\text {th }}$ of the time, to avoid the extremely large required price of SRMC in the peak times, because it's only $1 / 7$ of the time. The surprising point is that though peak times are infrequent, the prices and quantities at peak times determine which pricing arrangement is better for consumers.
\end{abstract}

\section{Keywords}

Globalization, Manufacturing, Business Cycle, Marginal-Cost Pricing, Output-Rate Flexibility

\section{World Economies Struggling with Overcapacity in Plant Assets}

World economies today are struggling with downturns in manufacturing and construction. The high-tech boom, digital technology, and new innovations have caused a massive shift in world economies from highly manufacturing-driven economies to massively service-driven economies. 
Table 1. \% Capacity utilization manufacturing USA.

\begin{tabular}{ccccccc}
\hline 1972-2016 Avg & $1988-89$ High & 1990-91 Low & $1994-95$ High & 2009 Low & 2016 May & 2017 May \\
78.4 & 85.6 & 77.3 & 84.6 & 63.7 & 75.0 & 75.5 \\
\hline
\end{tabular}

Source: https://www.federalreserve.gov/releases/g17/Current.

Employment in traditional manufacturing has fallen from some 40 percent post-World War II to about 15 percent today. The world is experiencing a depression in the manufacturing and construction industries. Table 1 shows statistics on the percentage capacity utilization manufacturing in the United States. Low percentage capacity utilization manufacturing rates support investors' economic views that now is not the time to build new factories.

\section{Globalization, Open-Market Systems Domestically and Internationally}

\subsection{What Is Globalization?}

Globalization is a process of interaction and integration among the people, companies, and governments of different nations, a process driven by international trade and investment and aided by information technology. Globalization increases under open-market systems domestically and internationally ${ }^{1}$.

Countries under open-market systems have large numbers of producers and buyers of goods and services each acting to his/her interest to secure profits and consumer welfare with minimal government interferrence/regulation.

\subsection{Currency Manipulation and Dumping}

Currency manipulations are acts of buyers and sellers of a country's currency to alter its market value to achieve a desired purpose. Currency manipulation seen today is similar to dumping, the selling of goods to a foreign market at a lower price than sold in the domestic market. The renown Professor Jacob Viner writes "Dumping may be maintained for long periods where its objective is to obtain the economies of full utilization of existing production facilities while charging a high price at home."

John M. Clark [1] writes ${ }^{3}$ on dumping:

"From the point of view of the foreigner, the chief objection to dumping arises from the fact that the cheap supplies cannot be relied on forever. Otherwise producers and consumers alike could adjust themselves to the blessings which the legerdemain of cost-accounting conjures into their laps, and the nation would be richer by the use of goods whose overhead costs

\footnotetext{
1"This current wave of globalization has been driven by policies that have opened economies domestically and internationally. In the years since the Second World War, and especially during the past two decades, many governments have adopted free-market economic systems, vastly increasing their own productive potential and creating myriad new opportunities for international trade and investment." http://www.globalization101.org/what-is-globalization/.

${ }^{2}$ Encyclopedia of the Social Sciences, The Macmillian Company, 1942, 5. 275.

${ }^{3}$ John M. Clark, 1923, page 423.
} 
they are not required to pay. When the goods which are dumped are raw materials, foreign producers may fatten their profits by using them, and perhaps sell the products back to the country from which the materials came. Producers who have to compete against dumping feel a grievance, especially as their markets are flooded at just the times when demand is weak and their efforts at stabilization are hampered. If the foreign country wishes to be self-sufficient it may be worth while for it to bear the immediate sacrifice involved in excluding goods which others wish to dump on them."

\section{John M. Clark: Overhead Costs and the Business Cycle}

John M. Clark (1884-1963) attributed the main problems of the business cycle to the dominant role of fixed costs that are incurred irrespective of output rates. John M. Clark [1] writes ${ }^{4}$ that overcapacity for the great majority of the time is normal and to be expected:

"What governs the supply of productive capacity in an industry?

... In the first place, owing to the forces already studied in connection with the business cycle, plant capacity is governed far more by the peak demand than by the minimum or the average. If this were not true, and if business did not build for the peak at the time of the upswing, one of the chief causes of business cycle would disappear. This very building for the peak, timed as it is, tends powerfully to increase the height of the peak itself.

... To sum up, it appears that there are strong forces at work which tend naturally to produce an oversupply of permanent capital, and there are decided indications that such as oversupply exists."

Fluctuations in manufacturing and construction are far more intense than fluctuations in demand for final goods and services. This is due to economic reasons that Clark [1] (1923, p. 389) explains well:

"The demand for means of production fluctuate more violently than that for finished consumers' goods, and also appears to fluctuate sooner, taking the lead in a way which would suggest that its changes are a cause, rather than an effect, of the changes in consumers' demand. In point of fact they are both effect and cause, as we shall see in a moment. Something similar is true of raw materials as compared to finished goods, while wholesale prices fluctuate more than retail... the physical need for new equipment shows a tendency to fluctuate more intensely than the demand for the finished product, because it depends, not upon the total volume of demand, but upon the rate of growth (or shrinkage): the amount added, for example, during the current year."

Clark is a business-cycle economist. Clark has insights today with the world in a general recession and with interest rates hovering over zero. Clark calls the

${ }^{4}$ John M. Clark, 1923, pages 437-439. 
down business cycle "the disease." Clark argues that farsighted and publicspirited managers must determine if society can meet peak-cycle demand, even though the peaks of the cycle are infrequent.

In my study on Clark and the US cement industry [2], I propose a definition of industry under-capacity: "Industry under-capacity exists if persistently, over considerable periods, there are acutely raised prices, product shortages, costs and inconveniences of waiting lines and higher costs of substitutes at times of high level or peak demand." With my definition industry under-capacity can exist even in a depression with rampant idle capacity. Why? Because the next business upturn will be stopped for lack of capacity to meet peak-cycle demand.

Clark's view is that low depression prices make the business cycle worse. Low prices lead to a further shrinkage of manufacturing and construction activities. What then is there to do during a depression? Clark is generally against price cutting during economic downturns, calling it suicidal. Globalization makes countries similar to two local supermarket chains. In a depression it doesn't pay for one chain to offer free bread. The other chain would simply match it and both chains would be worse off. Clark calls this spoiling the market.

The Talmud discusses a depression in wine and olive oil in Palestine and linen in Babylon, the manufacturing industries at the time, the major sources of income for the people. The Talmud calls for crying out to God when prices are ruinously low:

"Our Rabbis taught: Public prayers are offered for goods [which have become dangerously cheap], even on the Sabbath. R. Johanan said: For instance linen garments in Babylon and wine and oil in Palestine. R. Joseph said: This [is only so] when [these have become so] cheap that ten are sold at [the price of] six (Baba Bathra 91a)."

\section{A Model of Globalization}

\subsection{Monopoly Theory and Peak-Load Pricing}

Peak-load pricing has much in common with Clark's views on fixed costs and the business cycle. Crew et al [3] $(1995,216-217)$ write on peak-load pricing:

"Peak-load pricing refers to the pricing of economically non-storable commodities whose demand varies periodically. If price were uniform over time, quantity demanded would rise and fall periodically. To meet demand at the peak would then require the installation of capacity which is underutilized over the remainder of the cycle. Since the capacity is not costless, the resulting idleness during the off peak is the basis for the peak-load problem and the motivation for pricing to mitigate this inefficiency. [footnote] Peak-load pricing or joint product pricing might be considered an extreme form of economies of scope where, for the traditional one plant case, it certainly costs less to supply peak and off-peak demand by a single firm rather than have one firm supply peak demand and the other firm supply off-peak demand." 


\subsection{Applying Peak-Load Pricing to Globalization}

We illustrate globalization with a model of supply and demand, in two countries, Country $_{X}$ and Country $y_{Y}$ of a single product, $Q$, that has peak and off-peak demand periods. The product $Q$ is homogeneous in that all $Q$ units are assumed identical in the market. We assume two countries Country ${ }_{X}$ and Country ${ }_{Y}$ each with many manufacturers and buyers of $Q$. We assume that manufacturers and buyers of $Q$ in one country can sell and buy $Q$ with perfect ease in the second country. No country uses tariffs on imports or subsidies on exports. We assume no transportation costs. We assume $Q$ manufacturers know the consumerdemand schedules.

There can be only one price per $Q$ in any time period. Consumers pay market price times quantities purchased, $T R=P \times Q$ (total revenue to suppliers equals market price times quantities).

The demand curve shows the maximum quantities consumers would be willing to purchase at various prices. The assumption is that the demand curve is downward sloping, meaning that consumers would be willing to buy more $Q$ if prices were lower, all else being the same. The area under the demand curve up to the point of quantities of market purchases shows the value to the consumer.

\section{Conditions When Fixed Prices over the Cycle Increase Consumer Welfare}

\subsection{Objective of Proposition}

To prove in a mathematical model of fluctuating demand curves, $D_{w 1} D_{w 2}$, that a pricing scheme of a fixed price, $\bar{P}$, in both periods gives more expected consumer surplus, $E(C S)$, than an alternative pricing scheme: $P_{1}$ for off-peak periods and $P_{2}$ for the peak periods under conditions that consumers pay the same expected total revenue, $E(T R)$, and receive the same expected goods, $E(Q)$

\subsection{Proposition}

Proposition I Under conditions of fluctuating downward-sloping demand curves, with frequencies $w_{1}$ and $w_{2}$ where $w_{1}+w_{2}=1$, a comparison of alternative pricing schemes

A: $P_{1}$ for off-peak periods and $P_{2}$ for the peak period versus

B: $\bar{P}$ in both periods

shows $E(C S)_{B}-E(C S)_{A}>0$ which rises as demand elasticity rises under conditions

$$
E(T R)_{A}=E(T R)_{B}
$$

and

$$
E(Q)_{A}=E(Q)_{B}
$$

Proof:

The downward fluctuating demand curves make for: 


$$
P_{1}<\bar{P}<P_{2}
$$

and

$$
B_{1}<A_{1}<A_{2}<B_{2}
$$

By definition of $E(T R)$ :

$$
E(T R)_{A}=P_{1} A_{1} w_{1}+P_{2} A_{2} w_{2}
$$

and

$$
E(T R)_{B}=\bar{P}\left(B_{1} w_{1}+B_{2} w_{2}\right)
$$

By definition of $E(Q)$ :

$$
E(Q)_{A}=A_{1} w_{1}+A_{2} w_{2}
$$

and

$$
E(Q)_{B}=B_{1} w_{1}+B_{2} w_{2}
$$

By definition of $E(C S)$ :

$$
E(C S)_{A}=\left(C S_{A 1, P 1}\right)\left(w_{1}\right)+\left(C S_{A 2, P 2}\right)\left(w_{2}\right)
$$

and

$$
E(C S)_{B}=\left(C S_{B 1, \bar{P}}\right)\left(w_{1}\right)+\left(C S_{B 2, \bar{P}}\right)\left(w_{2}\right)
$$

By assumption (1) we can state:

$$
P_{1} A_{1} w_{1}+P_{2} A_{2} w_{2}=\bar{P}\left(B_{1} w_{1}+B_{2} w_{2}\right)
$$

By assumption (2) we can state:

$$
A_{1} w_{1}+A_{2} w_{2}=B_{1} w_{1}+B_{2} w_{2}
$$

Combining assumptions (1) and (2):

$$
P_{1} A_{1} w_{1}+P_{2} A_{2} w_{2}=\bar{P}\left(A_{1} w_{1}+A_{2} w_{2}\right)
$$

Rearranging:

$$
\left(\bar{P}-P_{1}\right) A_{1} w_{1}=\left(P_{2}-\bar{P}\right) A_{2} w_{2}
$$

Using letters of Figure 1 and Figure 2

$$
F G H I \times w_{1}=C D E F \times w_{2}
$$

We can state:

$$
E(C S)_{B}-E(C S)_{A}=\left(C S_{B 1, \bar{P}}\right)\left(w_{1}\right)+\left(C S_{B 2, \bar{P}}\right)\left(w_{2}\right)-\left(C S_{A 1, P 1}\right)\left(w_{1}\right)-\left(C S_{A 2, P 2}\right)\left(w_{2}\right)(16)
$$

Rearranging:

$E(C S)_{B}-E(C S)_{A}=\left(\left(C S_{B 2, \bar{P}}\right)-\left(C S_{A 2, P 2}\right)\right)\left(w_{2}\right)-\left(\left(C S_{A 1, P 1}\right)-\left(C S_{B 1, \bar{P}}\right)\right)\left(w_{1}\right)$

Using letters of Figure 1 and Figure 2:

$$
E(C S)_{B}-E(C S)_{A}=(C D E F+D E J) \times w_{2}-(F G H I-K G H) \times w_{1}
$$

Which reduces to:

$$
E(C S)_{B}-E(C S)_{A}=D E J \times w_{2}+K G H \times w_{1}
$$

$E(C S)_{B}-E(C S)_{A}$ must be greater than zero, providing that price elasticities 


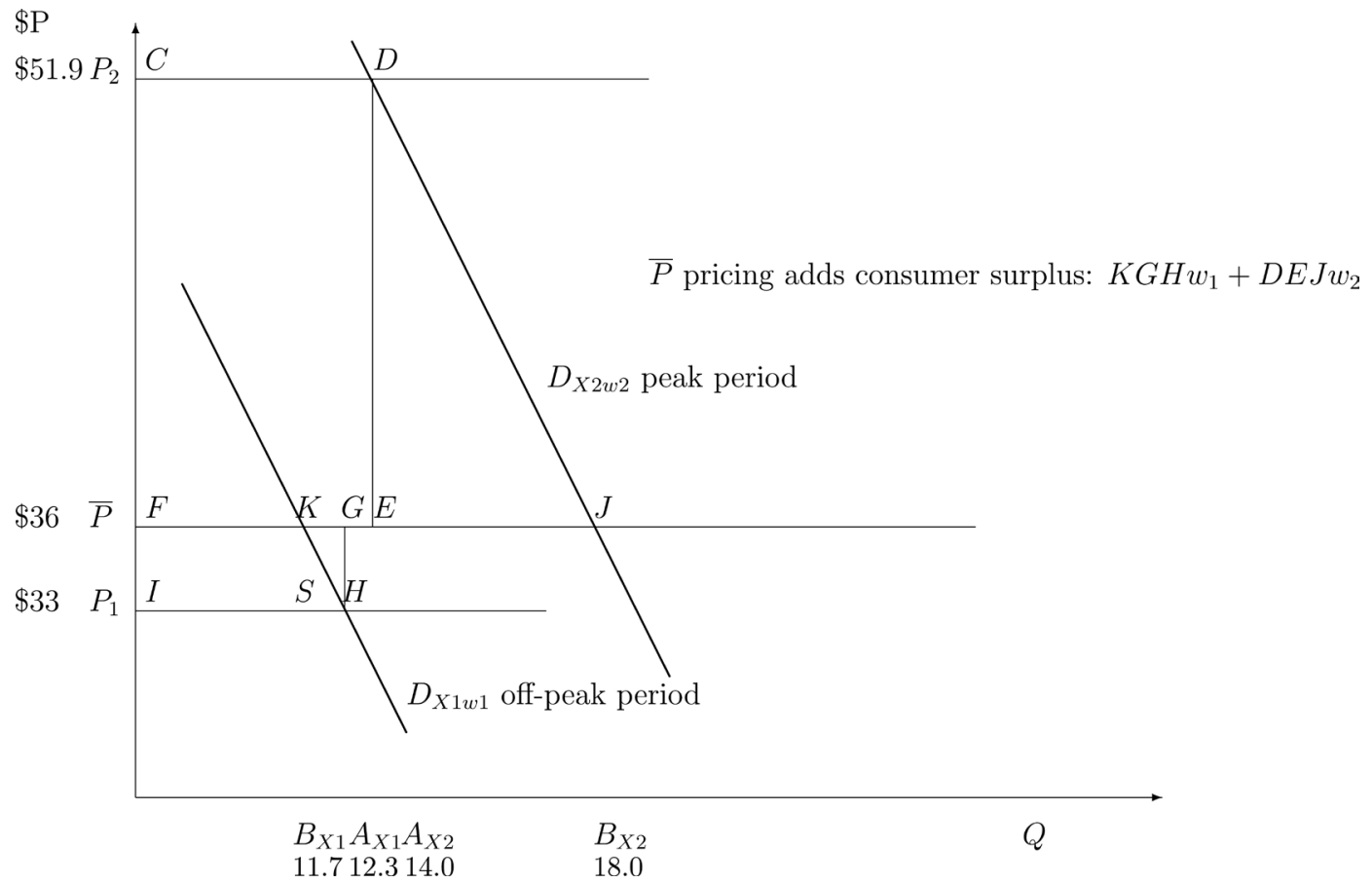

Figure 1. Country ${ }_{X}$ A varying prices v B fixed prices.

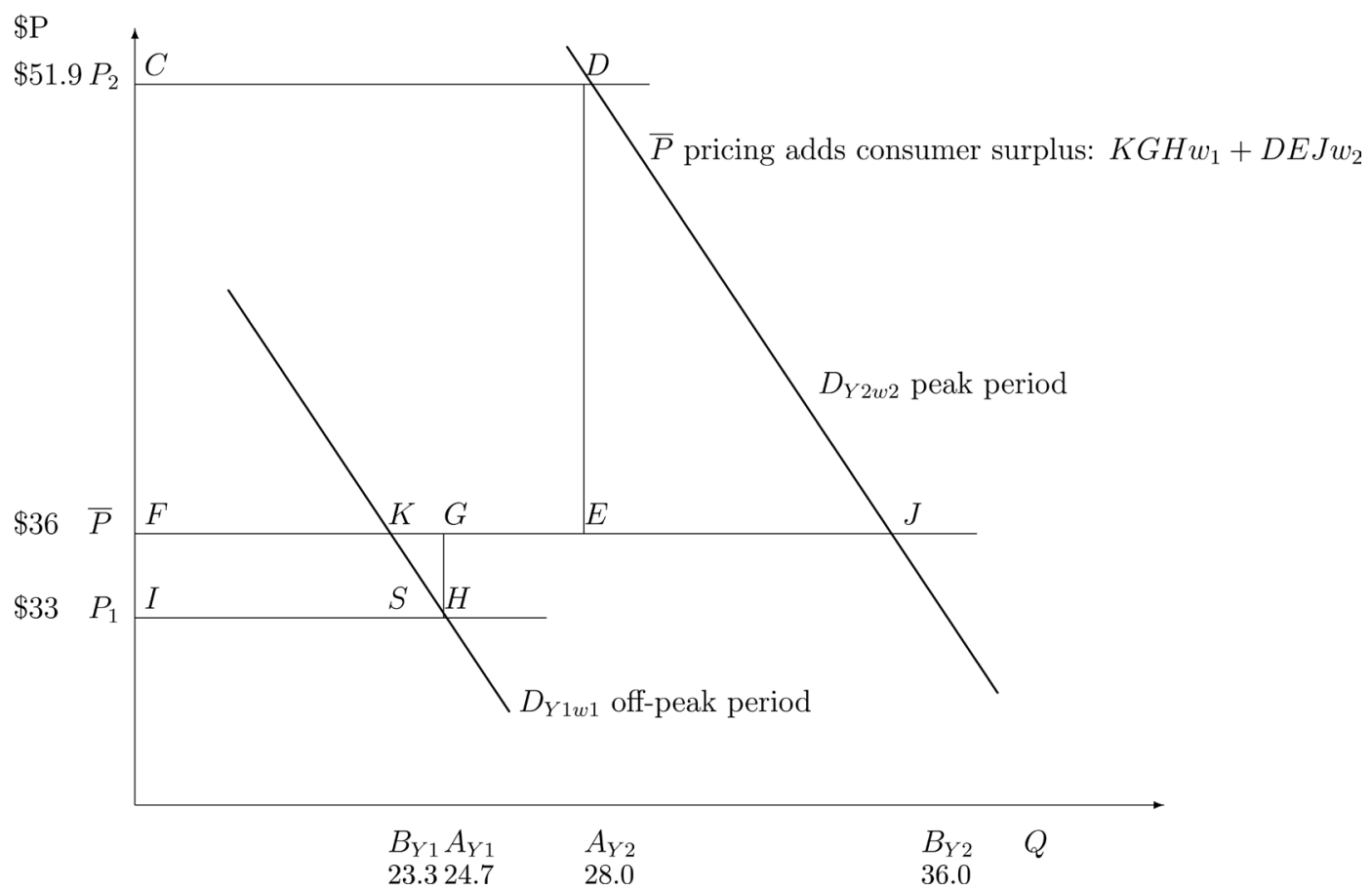

Figure 2. Country ${ }_{Y} \mathrm{~A}$ varying prices v B fixed prices.

of the demand curves are not zero. At zero price elasticity $B_{1}=A_{1}$ and $A_{2}=B_{2}$ and therefore $E(C S)_{B}-E(C S)_{A}=0$. Price elasticity $>0$ makes $E(C S)_{B}-E(C S)_{A}>0$ and rises as price elasticity rises.

\subsection{Numerical Example of Proposition in Countries $\mathrm{X}$ and $\mathrm{Y}$}

Adding volatility in goods, more in peak times and less in off-peak times, adds to 
expected consumer surplus if consumers pay the same expected amounts and get the same expected goods over the cycle. Though peaks are infrequent, people have a human preference for increasing the peaks. This adds to growth. Though the off-peaks are frequent they are less important to people concerned with growth, achievement and happiness. Machines are not like people. Machines prefer regularity while people prefer irregularity. I present a numerical example in two Countries, $X$ and $Y$, to make the economic points clearer.

I assume two countries Country ${ }_{X}$ and Country ${ }_{Y}$ each facing fluctuating demands, off-peak, with $w_{1}=6 / 7$ frequency and peak, with $w_{2}=1 / 7$ frequency. I assume a large country and a small country. I assume Country ${ }_{Y}$ is double the size of Country ${ }_{X}$ and has double the resources and the numbers of buyers and sellers of $\mathrm{Q}$.

Figure 1 shows a geometric demonstration for Country ${ }_{X}$ and Figure 2 shows a geometric demonstration for Country ${ }_{Y}$

Since manufacturers and buyers of $Q$ in Country $_{X}$ can sell and buy $Q$ with perfect ease in Country ${ }_{Y}$ there can be only one market price in both countries at the same time. I assume the varying prices, pricing alternative $A$, are $\$ 33$ in off-peak and $\$ 51.9$ in peak times. I assume the fixed price, pricing alternative $B$, is $\$ 36$. I assume $w_{1}=6 / 7$ and $w_{2}=1 / 7$.

Pricing alternative A, SRMC pricing, give more regularity of outputs, less volatility. In Country ${ }_{X}$ in Figure 1 with pricing alternative A, the outputs are 12.3 and 14.0. In Country ${ }_{Y}$ in Figure 2 with pricing alternative A, the outputs are 24.7 and 28.0.

Pricing alternative $\mathrm{B}$, fixed prices, give more irregularity of outputs, more volatility. In Country ${ }_{X}$ in Figure 1 with pricing alternative B, the outputs are 11.7 and 18.0. In Country ${ }_{Y}$ in Figure 2 with pricing alternative B, the outputs are 23.3 and 36.0.

In Country ${ }_{X}$ in Figure 1:

$$
\begin{aligned}
& E(Q)_{A}=6 / 7 \times 12.3+1 / 7 \times 14.0=12.6 \\
& E(Q)_{B}=6 / 7 \times 11.7+1 / 7 \times 18.0=12.6 \\
& E(T R)_{A}=6 / 7 \times 33 \times 12.3+1 / 7 \times 51.9 \times 14.0=\$ 451.7 \\
& E(T R)_{B}=6 / 7 \times 36 \times 11.7+1 / 7 \times 36 \times 18.0=\$ 451.7
\end{aligned}
$$

In Country ${ }_{Y}$ in Figure 2:

$$
\begin{aligned}
& E(Q)_{A}=6 / 7 \times 24.7+1 / 7 \times 28.0=25.2 \\
& E(Q)_{B}=6 / 7 \times 23.3+1 / 7 \times 36.0=25.2 \\
& E(T R)_{A}=6 / 7 \times 33 \times 24.7+1 / 7 \times 51.9 \times 28.0=\$ 906.3 \\
& E(T R)_{B}=6 / 7 \times 36 \times 23.3+1 / 7 \times 36 \times 36.0=\$ 904.1
\end{aligned}
$$

\section{Conclusions}

Today we have vast increases in world trade and marvelous new technology. Yet, we have low rates of capacity utilization in manufacturing and construction. We 
present a theoretical model of globalization, of two countries, $X$ and $Y$, each with open-market systems domestically and internationally. We compare two pricing policies in each country: short-run marginal cost pricing versus prices fixed over the business cycle. We prove in our model loss in expected consumer surplus with SRMC pricing and a gain with a fixed price. We give a detailed numerical example with graphs for each country. The main result is that fixing the price over the business cycle increases the volatility of $\mathrm{Q}$ demand over the cycle and increases consumer surplus in both countries under certain conditions.

Much of our work is based on John M. Clark. He argued against SRMC pricing in industries facing cyclical demand fluctuations. He wrote [4] (1961, pages 121-122) that with SRMC pricing in cyclical industries firms would be operating at a loss for the great majority of the time, with vain hopes of exploiting the infrequent peak times:

"It is decidedly doubtful whether it would be economically feasible to make profits enough in such periods to offset the losses incurred in normal and subnormal periods. And if it were economically feasible, there might be other serious obstacles and drawbacks in the way of exploiting the profitable periods by raising prices as graspingly as would be necessary to balance accounts."

Clark's last paragraph in his 1961 book [4], applies today:

"Meanwhile it remains true that the imperfectly competitive mixed economy we have is better than the impossible abstraction of perfect competition ... The system has serious shortcomings, but there is room to hope that our performance in these respects may be substantially improved, if all groups concerned attack the problems with a realization of their importance and with the necessary understanding and good will."

\section{Acknowledgements}

Special thanks to Paul Kleindorfer, Robert Brent, Dominick Salvatore, Eytan Sheshinski, Yekutiel Drori, and anonymous referees on earlier versions.

\section{References}

[1] Clark, J.M. (1923) Studies in the Economics of Overhead Costs. The University of Chicago Press, Chicago.

[2] Aranoff, G. (1991) John M. Clark's Concept of Too Strong Competition and a Possible Case: The U.S. Cement Industry. Eastern Economic Journal, 17, 45-60.

[3] Crew, M.A., Fernando, C.S. and Kleindorfer, P.R. (1995) The Theory of Peak-Load Pricing: A Survey. Journal of Regulatory Economics, 8, 215-248. https://doi.org/10.1007/BF01070807

[4] Clark, J.M. (1961) Competition as a Dynamic Process. The Brookings Institution, Washington DC. 
Submit or recommend next manuscript to SCIRP and we will provide best service for you:

Accepting pre-submission inquiries through Email, Facebook, LinkedIn, Twitter, etc. A wide selection of journals (inclusive of 9 subjects, more than 200 journals)

Providing 24-hour high-quality service

User-friendly online submission system

Fair and swift peer-review system

Efficient typesetting and proofreading procedure

Display of the result of downloads and visits, as well as the number of cited articles Maximum dissemination of your research work

Submit your manuscript at: http://papersubmission.scirp.org/

Or contact me@scirp.org 